\title{
Direct hydroxylation of benzene to phenol with hydrogen peroxide catalyzed by a quinine-heteropolyacid hybrid
}

\author{
Pingping Zhao, Yu Zhou, Yangqing Liu, Jun Wang* \\ State Key Laboratory of Materials-Oriented Chemical Engineering, College of Chemistry and Chemical Engineering, Nanjing University of Technology, \\ Nanjing 210009, Jiangsu, China
}

\section{A R T I C L E I N F O}

\section{Article history:}

Received 16 May 2013

Accepted 30 May 2013

Published 20 November 2013

Keywords:

Heteropolyacid

Polyoxometalate

Hydroxylation of benzene

Heterogeneous catalysis

Phenol

\begin{abstract}
A B S T R A C T
A new heterogeneous hybrid catalyst designed for direct hydroxylation of benzene to phenol was prepared through modification of Keggin-structured phosphovanadomolybdate with quinine. The structure of the catalyst was fully characterized by Fourier transform infrared and ultraviolet-visible spectroscopies, X-ray diffraction, scanning electron microscopy, thermogravimetric analysis, nitrogen sorption experiments, and CHN elemental analysis. The results indicated that the hybrid catalyst was a semi-amorphous heteropolyacid salt with high thermal stability, surface area, and pore volume. The catalytic activity of the hybrid for the hydroxylation of benzene with $\mathrm{H}_{2} \mathrm{O}_{2}$ was assessed. The hybrid catalyst forms a liquid-solid biphasic system and exhibits high activity, convenient recovery, and reusability. The strong electronic interactions and hydrogen bonding networks formed between the $\pi$-electron-rich quinine framework and heteropolyanions are responsible for the solid nature and insolubility of the catalyst. The high surface area and improved redox properties of the Keggin heteropolyacid account for its excellent catalytic performance. The results of this work reveal a new, more facile way to prepare an efficient polyoxometalate-based catalyst for heterogeneous hydroxylation of benzene to phenol.
\end{abstract}

(C) 2013, Dalian Institute of Chemical Physics, Chinese Academy of Sciences. Published by Elsevier B.V. All rights reserved.

\section{Introduction}

The three-step cumene process first reported by Hock and Lang [1] in 1944 is still widely used industrially to produce phenol even though it suffers from disadvantages including low atom utilization, high energy consumption, and environmental pollution [2]. Direct hydroxylation of benzene using clean oxidants like $\mathrm{N}_{2} \mathrm{O}$ [3], $\mathrm{O}_{2}$ [4], $\mathrm{H}_{2} \mathrm{O}_{2}$ [5], as well as the $\mathrm{H}_{2}-\mathrm{O}_{2}$ system with Pd-based composite membrane reactors [6,7] has attracted great attention even though it is one of the most difficult oxidation reactions in organic synthesis [6]. For $\mathrm{H}_{2} \mathrm{O}_{2}$-based hydroxylation of benzene, Schiff bases [8], molecular sieves including TS-1 and V-MCM-41 [9,10], and polyoxo- metalates (POMs) [11] have been used as catalysts. Among them, V-containing POM catalysts have shown high yields for phenol $[12,13]$. However, it is very difficult to isolate these catalysts because POMs readily dissolve in the reaction system. To prevent this issue, heterogenization of POMs is an interesting possibility to improve their potential for direct hydroxylation of benzene.

Immobilization of POMs on porous supports is commonly used to heterogenize POM catalysts. However, this approach always suffers from a slow reaction rate and/or leaching of active sites [14]. Recently, modification of POMs with organic units such as ionic liquids (ILs), organometallic complexes, and organic polymers has been used to prepare POM-based organ-

\footnotetext{
*Corresponding author. Tel: +86-25-83172264; E-mail: junwang@njut.edu.cn This work was supported by the National Natural Science Foundation of China (21136005). 
ic-inorganic hybrid heterogeneous catalysts [15-17]. We previously prepared a series of POM-based hybrid catalysts for use in many acid-catalyzed and oxidation organic syntheses [18-21]. Direct hydroxylation of benzene using functionalized IL- or cross-linked ionic copolymer-modified POM-based heterogeneous catalysts has been studied [22,23]. Although high activity and convenient recoverability were realized, complex steps and a large amount of organic solvent were required to prepare these catalysts. Pyridine-POM salts have also been employed as effective catalysts for direct hydroxylation of benzene [24]. The excellent performance of POM salts arises because the redox properties of the POM are improved by the stretch of conjugated $\pi$-electrons in the pyridine ring. However, pyridine-POM is a homogeneous catalyst for hydroxylation of benzene, which makes it difficult to isolate and reuse. Therefore, an environmentally friendly, simple to prepare, inexpensive, and highly efficient heterogeneous POM-based catalyst for direct hydroxylation of benzene remains a challenge.

In this work, we prepare a quinine-phosphovanadomolybdate $\left(\mathrm{H}_{5} \mathrm{PMo}_{10} \mathrm{~V}_{2} \mathrm{O}_{40}, \mathrm{~V}_{2}\right)\left(\mathrm{Q}-\mathrm{V}_{2}\right)$ solid-state hybrid catalyst by attaching a cinchona alkaloid structure composed of three basic molecular units: a quinoline ring, a quinuclidine ring (tertiary amine), and a methylenic alcohol group linking the two to Keggin-structured $\mathrm{V}_{2}$ using environmentally friendly $\mathrm{H}_{2} \mathrm{O}$ and ethanol as solvents (Scheme 1). We use this hybrid catalyst for direct hydroxylation of benzene to phenol with $\mathrm{H}_{2} \mathrm{O}_{2}$ as the oxidant. Although cinchona alkaloids are widely used in organic synthesis, they have not been investigated for direct hydroxylation of benzene. The $\mathrm{Q}-\mathrm{V}_{2}$ catalyst leads to the desirable liquid-solid heterogeneous hydroxylation of benzene systems, exhibiting high activity and good recyclability. In addition, the $\mathrm{Q}-\mathrm{V}_{2}$ catalyst possesses the advantages of being inexpensive, environmentally friendly, and convenient to prepare.

\section{Experimental}

\subsection{Catalyst preparation}

All chemicals were of analytical grade from Shanghai Chem.
Reagent Co. and used as received. Keggin-structured V-containing heteropolyacid (HPA) $\mathrm{V}_{2}$ was prepared according to a procedure described previously [24]. $\mathrm{MoO}_{3}$ (16.59 g, 0.115 mol) and $\mathrm{V}_{2} \mathrm{O}_{5}$ ( $2.10 \mathrm{~g}, 0.0115 \mathrm{~mol}$ ) were mixed with deionized water $(250 \mathrm{~mL})$ in a flask reactor equipped with a water-cooled condenser and magnetic stirrer, and then heated to $120^{\circ} \mathrm{C}$ under vigorous stirring. Concentrated $\mathrm{H}_{3} \mathrm{PO}_{4}$ (85\%, 1.33 g, 0.0115 mol) was dissolved in water $(10 \mathrm{~mL})$ and then added dropwise to the above mixture within $30 \mathrm{~min}$. After stirring for $24 \mathrm{~h}$ at $120{ }^{\circ} \mathrm{C}$, an orange-red solution formed. As the solution was cooled to room temperature, orange fine powder was got by a vacuum drying at $50{ }^{\circ} \mathrm{C}$ for $24 \mathrm{~h}$. The final product $\mathrm{PMoV}_{2}$ was obtained by re-crystalizing the powdered solid in deionized water and another vacuum drying at $50{ }^{\circ} \mathrm{C}$ for $24 \mathrm{~h}$.

The Q-V 2 solid-state hybrid was prepared through the reaction of quinine and $V_{2}$ with a molar ratio of 2.5:1 in water. The obtained orange precipitate was filtered, washed with distilled water $(4 \times 100 \mathrm{~mL})$, and then dried under vacuum at $80{ }^{\circ} \mathrm{C}$ for $24 \mathrm{~h}$ to give $\mathrm{Q}-\mathrm{V}_{2}$ as a powder (yield: $92 \%$ ). Its BET specific surface area was $27 \mathrm{~m}^{2} / \mathrm{g}$. Elemental analysis (\%) Calcd: C, 23.59; N, 2.75; H, 2.36. Found: C, 23.95; N, 2.83; H, 2.78.

Control materials, $[\mathrm{TMA}]_{5}-\mathrm{V}_{2}, \mathrm{Py}_{5}-\mathrm{V}_{2}$, and [quinoline $]_{5}-\mathrm{V}_{2}$, the chemical structure of which is presented in Scheme 2, were prepared similarly by reacting the respective organic precursor with $\mathrm{V}_{2}$ in a molar ratio of 5:1. The classical heterogeneous supported catalyst $\mathrm{PMoV}_{2} / \mathrm{SiO}_{2}$ was prepared by impregnating porous silica gel with $\mathrm{V}_{2}$. The measured BET specific surface area of $\mathrm{PMoV}_{2} / \mathrm{SiO}_{2}$ was $242 \mathrm{~m}^{2} / \mathrm{g}$ with an estimated vanadium loading of $0.23 \mathrm{mmol} / \mathrm{g}$ from inductively coupled plasmaatomic emission spectrometry (ICP-AES) analysis.

\subsection{Catalyst characterization}

Fourier transform infrared (FT-IR) spectra were recorded on a Nicolet 360 FT-IR spectrometer (KBr discs) in the region of 4000-400 $\mathrm{cm}^{-1}$. Elemental analyses were performed on a CHN elemental analyzer (FlashyEA 1112). The vanadium loading in the supported catalyst was determined by ICP-AES (Jarrell-Ash 1100). Electron spin resonance (ESR) spectra were

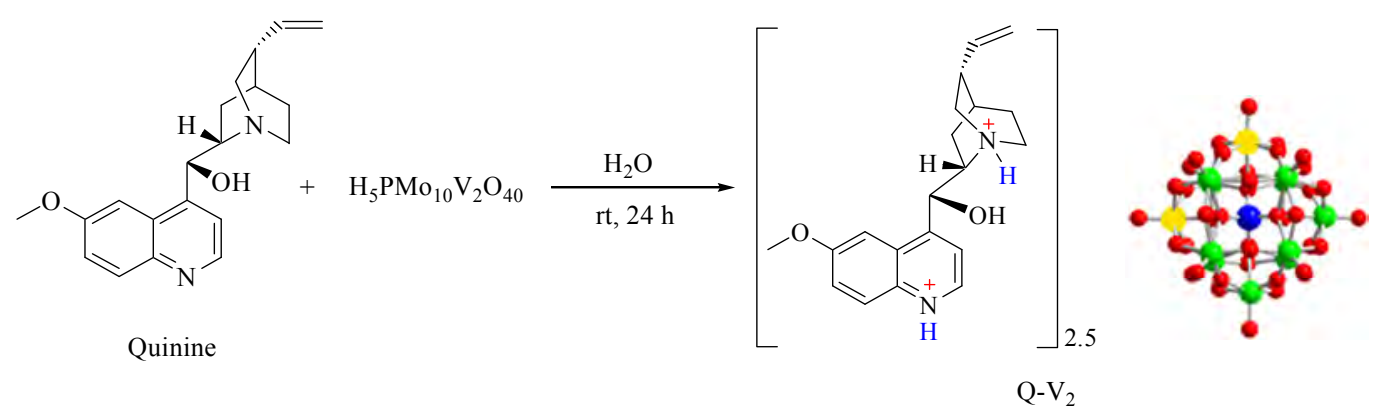

Scheme 1. Synthesis of quinine-doped heteropolyacid salt $Q-V_{2}$.

$$
\begin{aligned}
& {[-\underset{+}{\mathrm{NH}}]_{5} \mathrm{PMo}_{10} \mathrm{~V}_{2} \mathrm{O}_{40}{ }^{5-} \quad[\overbrace{+}^{\mathrm{NH}}]_{5} \mathrm{PMo}_{10} \mathrm{~V}_{2} \mathrm{O}_{40}{ }^{5-}} \\
& \text { [TMA } \left.]_{5}-\mathrm{V}_{2} \quad \mathrm{Py}_{5}-\mathrm{V}_{2} \quad \text { [quinoline }\right]_{5}-\mathrm{V}_{2}
\end{aligned}
$$

Scheme 2. Control organic-doped HPA salt catalysts. 
recorded on a Bruker EMX-10/12 spectrometer at X-band. Measurements were performed at $-110{ }^{\circ} \mathrm{C}$ in a frozen solution using a liquid/gas nitrogen temperature regulation system controlled by a thermocouple located at the bottom of the microwave cavity within a Dewar insert. Solid ultraviolet-visible (UV-Vis) spectra were obtained with a PE Lambda 950 spectrometer, and $\mathrm{BaSO}_{4}$ was used as an internal standard. X-ray diffraction (XRD) patterns were collected on a Bruker D8 Advance powder diffractometer using a $\mathrm{Ni}$-filtered $\mathrm{Cu} K_{\alpha}$ radiation source from $5^{\circ}$ to $50^{\circ}$ with a scan rate of $2^{\circ} / \mathrm{min}$ at $40 \mathrm{kV}$ and $20 \mathrm{~mA}$. The samples were pre-dried at $100^{\circ} \mathrm{C}$ for $2 \mathrm{~h}$ before measurement. BET surface areas were measured at the temperature of liquid nitrogen using a Micromeritics ASAP 2010 analyzer. The samples were degassed at $150{ }^{\circ} \mathrm{C}$ to a vacuum of 10-3 Torr before analysis. Scanning electron microscopy (SEM) was performed on a Hitachi S-4800 field-emission scanning electron microscope. Thermogravimetric (TG) analysis was carried out with a Netzsch STAY 409 instrument in dry air at a heating rate of $10^{\circ} \mathrm{C} / \mathrm{min}$.

\subsection{Catalytic test}

Benzene (0.78 g, $10 \mathrm{mmol})$, a mixture of acetonitrile and acetic acid (volume ratio 1:1, $6 \mathrm{~mL}$ ), and catalyst $(0.1 \mathrm{~g})$ were added to a $25 \mathrm{~mL}$ flask reactor. Then, aqueous $\mathrm{H}_{2} \mathrm{O}_{2}$ (30\%, 30 mmol) was added dropwise to the stirred mixture in the reactor within $30 \mathrm{~min}$. The reaction time began after the addition of $\mathrm{H}_{2} \mathrm{O}_{2}$. Typical reaction temperature and time were $70{ }^{\circ} \mathrm{C}$ and 4 $h$, respectively. After reaction, the mixture was centrifuged to remove the solid catalyst, and then the liquid was analyzed by a gas chromatograph (GC; SP-6890A) equipped with a flame ionization detector and capillary column (SE-54 $30 \mathrm{~m} \times 0.32 \mathrm{~mm} \times$ $0.3 \mu \mathrm{m})$. The temperature of the GC column oven was held at 70 ${ }^{\circ} \mathrm{C}$ for $5 \mathrm{~min}$ and then increased to $140{ }^{\circ} \mathrm{C}$ at a rate of $6{ }^{\circ} \mathrm{C} / \mathrm{min}$. Under these conditions, only phenol was detected as a product. No GC signals from catechol, hydroquinone, or benzoquinone were observed, i.e., the selectivity for phenol was $100 \%$. 1,4-Dioxane was used as an internal standard to calculate the yield of phenol (yield of phenol (based on benzene) $=$ mmol phenol/mmol initial benzene).

To test the catalytic recyclability of $Q-V_{2}$, after reaction, the catalyst was separated by filtration, washed with acetic acid (3 $\times 20 \mathrm{~mL}$ ) and then dried under vacuum at $80{ }^{\circ} \mathrm{C}$ for $6 \mathrm{~h}$. The recovered catalyst was reused in the next run.

\section{Results and discussion}

\subsection{Catalytic performance of $Q-V_{2}$ for hydroxylation of benzene}

Table 1 compares the performance of the various catalysts for hydroxylation of benzene with $\mathrm{H}_{2} \mathrm{O}_{2}$. No phenol was detected in the absence of catalyst (entry 1 ) or by using quinine or $\mathrm{V}$-free $\mathrm{H}_{3} \mathrm{PMo}_{12} \mathrm{O}_{40}$ as the catalyst (entries 2 and 3). When pure $\mathrm{V}_{2}$ was used as the catalyst, a yield of phenol of $24.5 \%$ with selective conversion of $\mathrm{H}_{2} \mathrm{O}_{2}$ of $8.2 \%$ was achieved (entry 4), which is consistent with previous reports that show the $\mathrm{V}$ ions in HPA anions are catalytically active centers for hydrox- ylation of benzene to phenol $[12,13]$. However, pure $V_{2}$ is a homogeneous catalyst that is difficult to isolate and reuse. In contrast, the quinine-doped catalyst $\mathrm{Q}-\mathrm{V}_{2}$ remained insoluble throughout the hydroxylation reaction, thus forming a liquid-solid heterogeneous catalysis system. Using $\mathrm{Q}-\mathrm{V}_{2}$, the yield of phenol was $23.6 \%$, and the selective conversion of $\mathrm{H}_{2} \mathrm{O}_{2}$ was $7.9 \%$ (entry 5). Such catalytic performance is comparable to that of homogeneous $V_{2}$, suggesting that heterogenization does not cause a significant decrease in the activity of $V$ species.

For comparision, the conventional heterogeneous catalyst $\mathrm{PMoV}_{2} / \mathrm{SiO}_{2}$ was prepared by supporting $\mathrm{V}_{2}$ on porous silica via impregnation. Low catalytic activity was observed for this catalyst: the phenol yield was $13.8 \%$ and the selective conversion of $\mathrm{H}_{2} \mathrm{O}_{2}$ was $4.6 \%$ (entry 6 ), consistent with previous results [22-26]. The above observations indicate that the quinine-doped organic HPA salt $\mathrm{Q}-\mathrm{V}_{2}$ not only generates a heterogeneous catalytic system but also maintains similar activity to its homogeneous analog. In addition, $\mathrm{Q}-\mathrm{V}_{2}$ is much more active and efficient than the conventional heterogeneous catalyst obtained by impregnation.

To clearly illustrate the role of quinine, three control samples, $[\mathrm{TMA}]_{5}-\mathrm{V}_{2}, \mathrm{Py}_{5}-\mathrm{V}_{2}$, and [quinoline $]_{5}-\mathrm{V}_{2}$, were prepared using different organic modifiers. For example, a $24.3 \%$ yield of phenol and selective conversion of $\mathrm{H}_{2} \mathrm{O}_{2}$ of $8.1 \%$ were obtained using the known organic HPA salt of the quaternary amine cation $[\mathrm{TMA}]_{5}-\mathrm{V}_{2}$ (entry 7). Notably, $[\mathrm{TMA}]_{5}-\mathrm{V}_{2}$ was insoluble during the early stage of the reaction but it dissolved gradually upon the addition of $\mathrm{H}_{2} \mathrm{O}_{2}$, resulting in a homogeneous reaction. Pyridine-doped catalyst $\mathrm{Py}_{5}-\mathrm{V}_{2}$ (entry 8) prepared by directly mixing Py with $\mathrm{V}_{2}$ also induced a homogeneous reaction but gave a lower yield and selective conversion of $\mathrm{H}_{2} \mathrm{O}_{2}$ than [TMA $]_{5}-\mathrm{V}_{2}$. Control catalyst [quinoline] $]_{5}-\mathrm{V}_{2}$ (entry 9) contained similar quinine structure to $\mathrm{Q}-\mathrm{V}_{2}$, but it still formed a homogeneous reaction system, giving a phenol conversion of $22.4 \%$ and selective conversion of $\mathrm{H}_{2} \mathrm{O}_{2}$ of $7.5 \%$. These results indicate that it is not easy to prepare insoluble, doped organic HPA salt catalysts for the heterogeneous hydroxylation of benzene with $\mathrm{H}_{2} \mathrm{O}_{2}$. This is mainly because Keggin-structured HPA catalysts

Table 1

Performance of various catalysts for the hydroxylation of benzene with $\mathrm{H}_{2} \mathrm{O}_{2}$.

\begin{tabular}{|c|c|c|c|c|}
\hline Entry & Catalyst & Reaction type & $Y^{\mathrm{a}} / \%$ & $X\left(\mathrm{H}_{2} \mathrm{O}_{2}\right)^{\mathrm{b}} / \%$ \\
\hline 1 & none & homogeneous & 0 & 0 \\
\hline 2 & quinine & homogeneous & 0 & 0 \\
\hline 3 & $\mathrm{H}_{3} \mathrm{PMo}_{12} \mathrm{O}_{40}$ & homogeneous & 0 & 0 \\
\hline 4 & $\mathrm{~V}_{2}$ & homogeneous & 24.5 & 8.2 \\
\hline 5 & $\mathrm{Q}-\mathrm{V}_{2}$ & heterogeneous & 23.6 & 7.9 \\
\hline 6 & $\mathrm{PMoV}_{2} / \mathrm{SiO}_{2}$ & heterogeneous & 13.8 & 4.6 \\
\hline 7 & {$[\mathrm{TMA}]_{5}-\mathrm{V}_{2}$} & homogeneous & 24.3 & 8.1 \\
\hline 8 & $\mathrm{Py}_{5}-\mathrm{V}_{2}$ & homogeneous & 21.2 & 7.1 \\
\hline 9 & [quinoline] ${ }_{5}-\mathrm{V}_{2}$ & homogeneous & 22.4 & 7.5 \\
\hline
\end{tabular}

Reaction conditions: catalyst $0.04 \mathrm{mmol}$ for entries $1-5$ and $7-9 ; 0.35 \mathrm{~g}$ for entry 6), benzene (10 mmol), mixture of acetonitrile and acetic acid ( $6 \mathrm{~mL}$, volume ratio of $1: 1), 30 \% \mathrm{H}_{2} \mathrm{O}_{2}(30 \mathrm{mmol}), 70^{\circ} \mathrm{C}, 4 \mathrm{~h}$.

aYield of phenol $=n($ phenol $) / n_{0}($ benzene $)$.

bSelective conversion of $\mathrm{H}_{2} \mathrm{O}_{2}=n($ phenol $) / n_{0}\left(\mathrm{H}_{2} \mathrm{O}_{2}\right)$. 
tend to be labile, degradable, and/or soluble in the presence of $\mathrm{H}_{2} \mathrm{O}_{2}$ [27]. Therefore, during the heterogenization process, quinine plays the important role of keeping the catalyst insoluble in the reaction system.

\subsection{Catalyst reusability}

The reusability of a heterogeneous catalyst is important, so we measured the catalytic recyclability of $\mathrm{Q}-\mathrm{V}_{2}$ using a four-run test, as shown in Fig. 1. In each cycle, the catalyst $Q-V_{2}$ was recovered by filtration from the reaction mixture, dried, and then directly used in the next cycle without further treatment. The recovery ratio of the catalyst was greater than $90 \%$. If no fresh catalyst was added to the recovered catalyst, the yield of phenol decreased slowly as the catalyst was reused numerous times (Fig. 1), with yields of $20.5 \%, 16.4 \%$, and $15.8 \%$ for the second, third, and fourth runs, respectively. The slow decrease of yield is attributed to the loss of some catalytic active sites during reaction and recovery rather than to a decrease of activity caused by the formation of coke in the reaction or distortion of the catalyst structure.

When a small amount of fresh catalyst was added to the recovered one to keep the amount of catalyst in each run constant, the yield of phenol was $22.8 \%, 20.4 \%$, and $21.2 \%$ for the second, third, and fourth runs, respectively. Although the catalytic activity still reduced slightly for each cycle, the deactivation rate of the catalyst was considerably slower than when no fresh catalyst was added (Fig. 1). This phenomenon indicates that the heterogeneous catalyst $\mathrm{Q}-\mathrm{V}_{2}$ can be reused effectively after simple filtration. Meanwhile, this again proposes that the decrease of activity of the recovered catalyst is caused by the leaching of catalytic active centers, unlike conventional supported catalysts, which are deactivated mostly because of coke formation [28].

\subsection{Understanding catalytic performance}

Elemental analysis of $\mathrm{Q}-\mathrm{V}_{2}$ indicated that it forms with an initial molar ratio of quinine to $\mathrm{V}_{2}$ of 2.5:1. Elemental analysis of the recovered catalyst after four runs gave similar values to

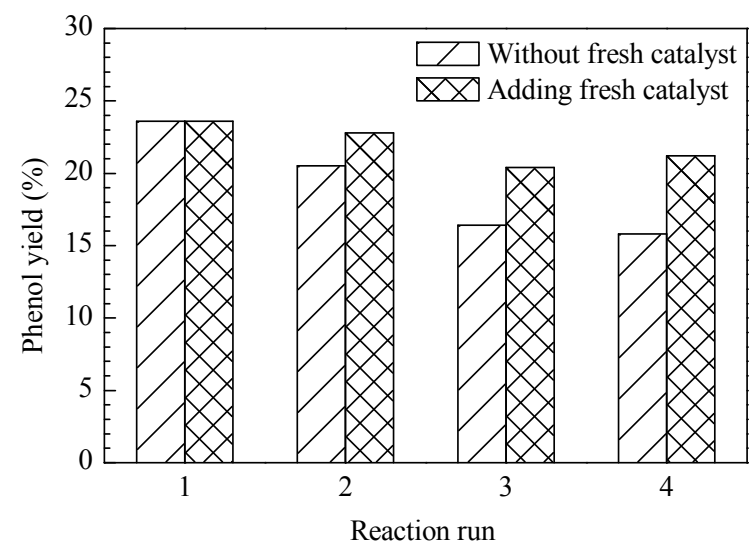

Fig. 1. Reusability of $Q-V_{2}$ catalyst for the hydroxylation of benzene with $\mathrm{H}_{2} \mathrm{O}_{2}$. Reaction conditions: molar ratio of $\mathrm{H}_{2} \mathrm{O}_{2}$ to benzene $=3: 1$, mixture of acetonitrile and acetic acid (volume ratio $1: 1,6 \mathrm{~mL}$ ), $70^{\circ} \mathrm{C}, 4$ h.

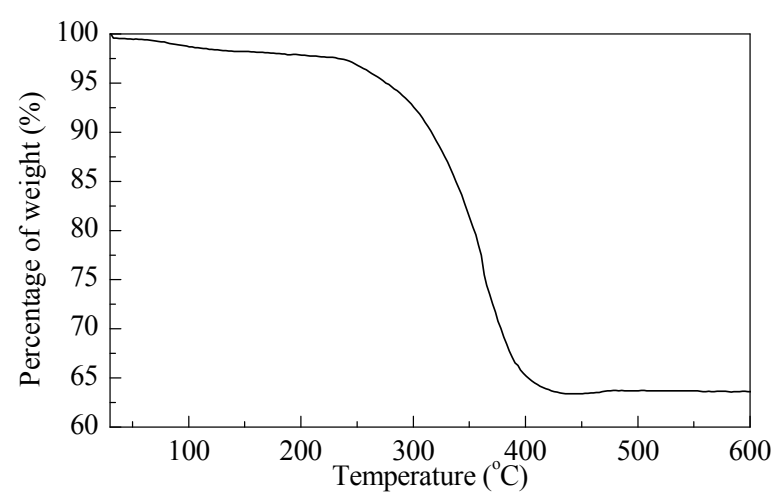

Fig. 2. TG curve measured for $\mathrm{Q}-\mathrm{V}_{2}$.

those determined for the fresh catalyst. This suggests that coking does not occur during the catalytic reaction. Figure 2 displays a TG curve measured for $\mathrm{Q}-\mathrm{V}_{2}$. The slight mass loss below $230{ }^{\circ} \mathrm{C}$ is assigned to the desorption of adsorbed water, suggesting high thermal stability of up to $230^{\circ} \mathrm{C}$. The drastic mass loss observed above $230{ }^{\circ} \mathrm{C}$ is attributed to the complete decomposition of the organic moiety, as well as the subsequent collapse of the inorganic HPA structure. The total mass loss is $34 \%$ in the range of $230-430{ }^{\circ} \mathrm{C}$, consistent with the theoretical prediction of $33.5 \%$. These results further confirm that the structure of $\mathrm{Q}-\mathrm{V}_{2}$ shown in Scheme 1 is correct.

XRD patterns of $V_{2}$ and $Q-V_{2}$ are depicted in Fig. 3. Pure $V_{2}$ presents a set of diffraction peaks consistent with the secondary structure of an inorganic HPA crystal [22]. However, for the hybrid catalyst $\mathrm{Q}-\mathrm{V}_{2}$, these characteristic peaks disappear, and only a weak, broad diffraction of around $7.8^{\circ}$ is observed, which implies that during the synthesis of $\mathrm{Q}-\mathrm{V}_{2}$, the crystal structure of the HPA precursor is rearranged by introducing the large organic cation quinine, affecting the self-assembly of cations and anions through electrostatic interactions, hydrogen bonds, and Van der Waals forces [29].

Figure 4 shows a nitrogen sorption isotherm measured for $\mathrm{Q}-\mathrm{V}_{2}$, which is type IV with a small hysteresis loop in the $p / p_{0}$ from 0.08 to 1.0 , suggesting typical mesostructure with relative large pore size (the average pore size is $39 \mathrm{~nm}$, Table 2). Based on the desorption branch of the isotherm, $\mathrm{Q}-\mathrm{V}_{2}$ has a high BET surface area of $27 \mathrm{~m}^{2} / \mathrm{g}$ and large pore volume of $0.27 \mathrm{~cm}^{3} / \mathrm{g}$, which are much higher than those of pure $V_{2}$ with a surface area of $10 \mathrm{~m}^{2} / \mathrm{g}$ and pore volume of $0.036 \mathrm{~cm}^{3} / \mathrm{g}$ (Table 2).

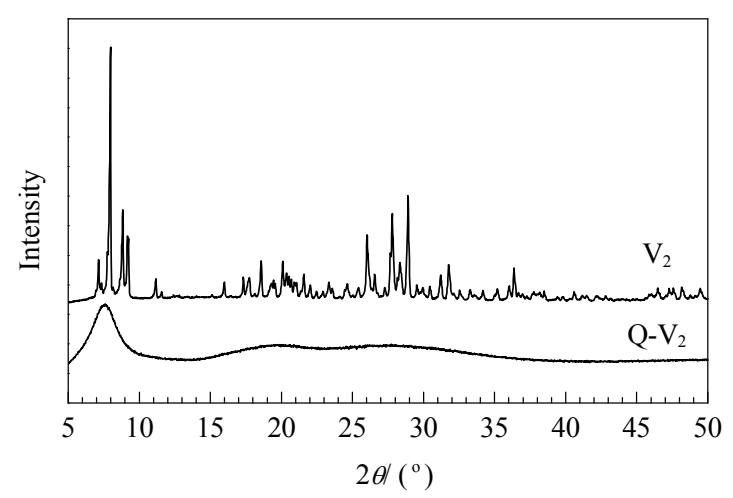

Fig. 3. XRD patterns measured for $\mathrm{V}_{2}$ and $\mathrm{Q}-\mathrm{V}_{2}$. 


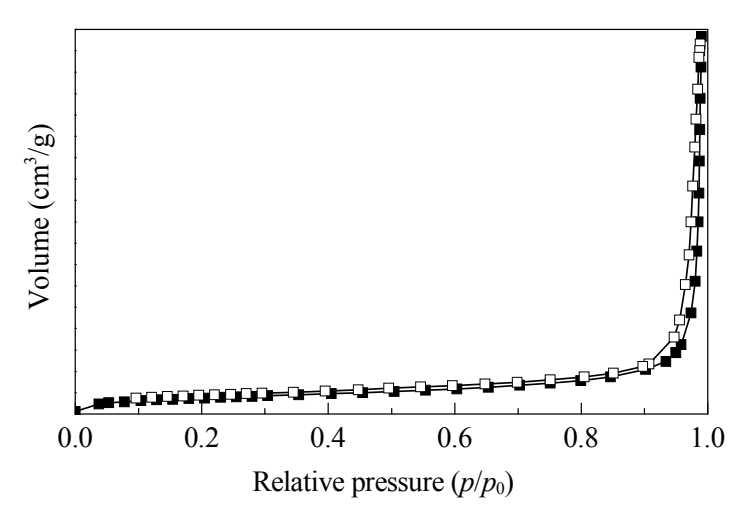

Fig. 4. Nitrogen adsorption-desorption isotherm measured for $\mathrm{Q}-\mathrm{V}_{2}$.

Table 2

Nitrogen sorption results of catalysts.

\begin{tabular}{lccc}
\hline Catalyst & $\begin{array}{c}A_{\mathrm{BET}} \\
\left(\mathrm{m}^{2} / \mathrm{g}\right)\end{array}$ & $\begin{array}{c}\text { Pore volume } \\
\left(\mathrm{cm}^{3} / \mathrm{g}\right)\end{array}$ & $\begin{array}{c}\text { Average pore diameter } \\
(\mathrm{nm})\end{array}$ \\
\hline $\mathrm{V}_{2}$ & 10 & 0.036 & 15 \\
$\mathrm{Q}-\mathrm{V}_{2}$ & 27 & 0.27 & 39 \\
\hline
\end{tabular}

Figure 5 shows the SEM images of $\mathrm{Q}-\mathrm{V}_{2}$ before and after four runs. The fresh catalyst possesses sponge-like morphology, and the small particles interact with each other to form mesopores, consistent with the nitrogen sorption results. In contrast, the recovered catalyst partly changes to a layered structure (Fig. 5(b)), which may be responsible for the decrease in activity of the recovered catalyst.

Generally, the activity of a heterogeneous catalyst is limited by mass transfer during the diffusion process. The heterogeneous $\mathrm{Q}-\mathrm{V}_{2}$ catalyst exhibits the similar performance to its homogeneous analog. The cavities between cations and anions may allow the substrates and oxidant $\mathrm{H}_{2} \mathrm{O}_{2}$ to permeate into the bulk of the catalyst structure [29], through which the well-known catalytic intermediate $\mathrm{V}^{5+}$ peroxo species in the bulk of the catalyst could act as the active centers for hydroxylation of benzene, i.e., the heterogeneous reaction takes place via typical bulk-type catalysis. In addition, the increased surface area and presence of mesopores in $\mathrm{Q}-\mathrm{V}_{2}$ allow easy diffusion and access of the substrate and oxidant $\mathrm{H}_{2} \mathrm{O}_{2}$ molecules to the HPA framework [30] and promote pseudoliquid behavior. Therefore, heterogeneous $\mathrm{Q}-\mathrm{V}_{2}$ can retain high catalytic activity even after four cycles of use.

FT-IR spectra of the catalysts are illustrated in Fig. 6. Four

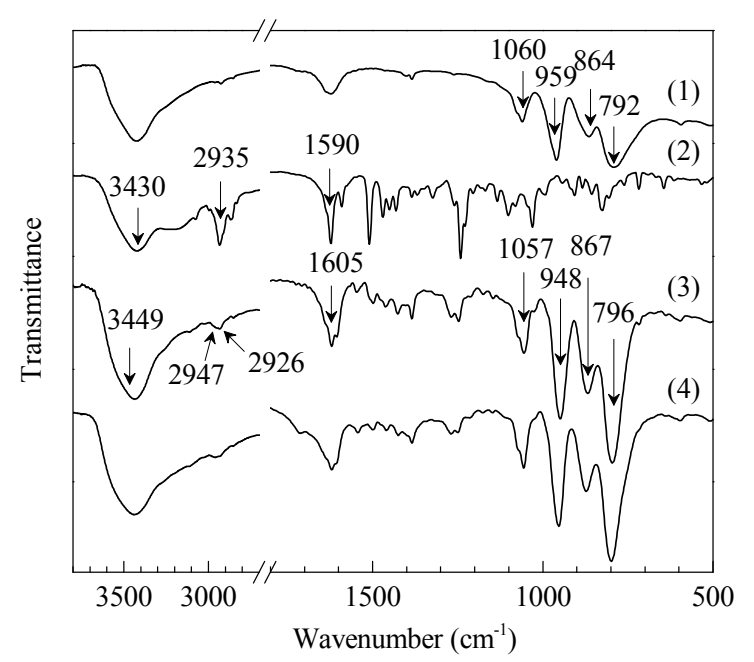

Fig. 6. FT-IR spectra of $V_{2}(1)$, quinine (2), $Q-V_{2}$ (3), and recycled $Q-V_{2}$ after four runs (4).

characteristic bands are observed at 1060, 959, 864, and 792 $\mathrm{cm}^{-1}$ for pure $\mathrm{V}_{2}$ (Fig. 6(1)) with Keggin structure, which are assigned to the asymmetric stretching vibrations of the central oxygen bond ( $\mathrm{P}-\mathrm{O})$ for $\mathrm{PO}_{4}$ tetrahedra, terminal oxygen $(\mathrm{M}=0)$, and inter- and intra-octahedral oxygen ( $\mathrm{M}-\mathrm{O}_{\mathrm{b}}-\mathrm{M}$ and $\left.\mathrm{M}-\mathrm{O}_{\mathrm{c}}-\mathrm{M}\right)$, respectively [31]. For the hybrid catalyst $Q-V_{2}$ (Fig. 6(3)), the four bands characteristic of HPA ions with Keggin structure can be still detected, suggesting that the Keggin framework remains even after the protons of HPA are substituted by organic cations. However, these peaks shift slightly, implying slight distortion of the Keggin HPA framework caused by the extension of the conjugated electrons of organic cations to HPA anions [32]. Meanwhile, the FT-IR spectrum of quinine shows the $\mathrm{C}=\mathrm{N}$ stretch of the quinoline ring at $1590 \mathrm{~cm}^{-1}$ (Fig. 6(2)). This peak shifts to $1605 \mathrm{~cm}^{-1}$ for $\mathrm{Q}-\mathrm{V}_{2}$ because of protonation [33]. The FT-IR results suggest that $\mathrm{Q}-\mathrm{V}_{2}$ is composed of ionically linked protonated quinine cations and Keggin-structured HPA anions.

The broad bands observed at 3430 and $2935 \mathrm{~cm}^{-1}$ for quinoline (Fig. 6(2)) assigned to $\mathrm{H}-\mathrm{O}$ vibrations and aliphatic $\mathrm{C}-\mathrm{H}$ stretching vibration, respectively, shift to $3449 \mathrm{~cm}^{-1}$ and split clearly into two bands at 2947 and $2926 \mathrm{~cm}^{-1}$ for Q- $V_{2}$. These results indicate the formation of extended hydrogen-bonding networks between HPA anions and organic cations [34]. These hydrogen-bonding networks, as well as the large volume and high valence of HPA anions, may account for the solid nature of
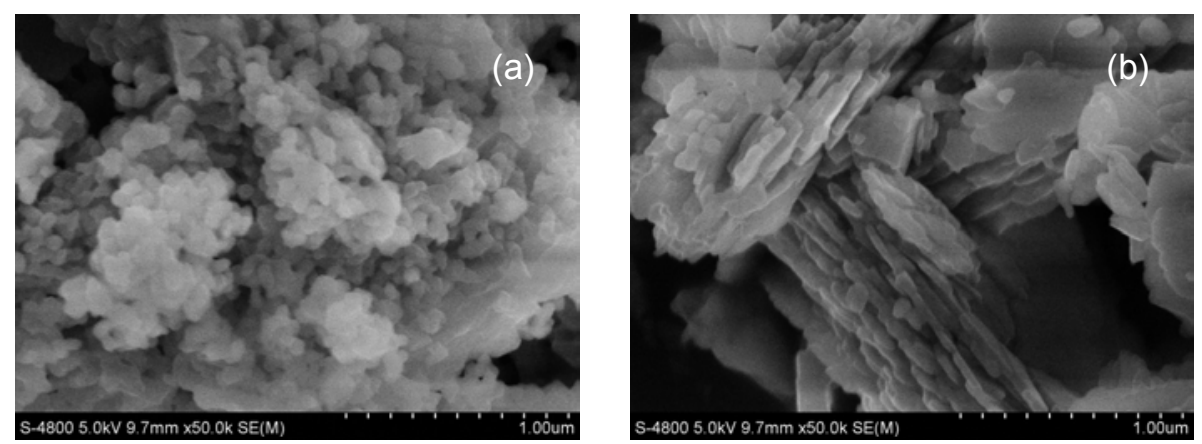

Fig. 5. SEM images of fresh catalyst $Q-V_{2}(a)$ and recycled $Q-V_{2}$ after four runs (b). 

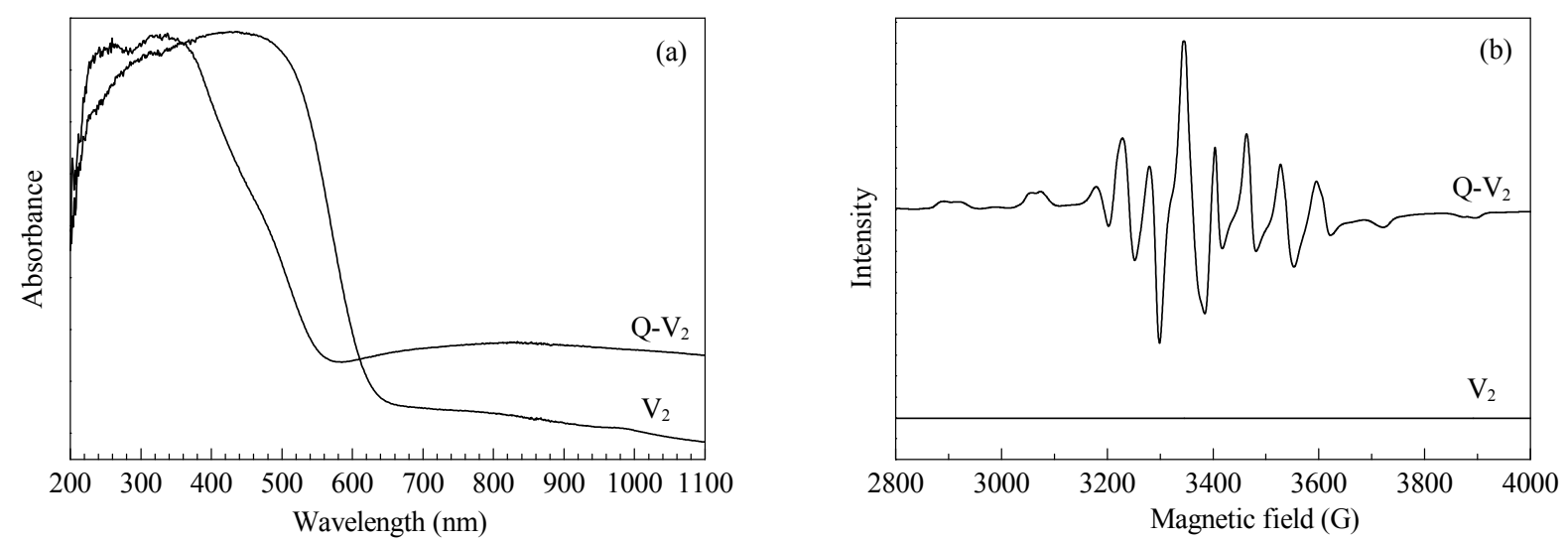

Fig. 7. UV-Vis spectra (a) and ESR spectra (b) of $V_{2}$ and $Q-V_{2}$.

the hybrid catalyst $\mathrm{Q}-\mathrm{V}_{2}$. Meanwhile, the hydroxyl groups in the quinine structure favor the adsorption of $\mathrm{H}_{2} \mathrm{O}_{2}$ during the catalytic reaction, resulting in a considerable increase of catalytic activity, which is in good agreement with results published previously showing that the hydrophilicity/hydrophobicity of a catalyst will affect its activity [35]. The recovered $\mathrm{Q}-\mathrm{V}_{2}$ catalyst (Fig. 6(4)) exhibits similar bands to the fresh one, indicating that the chemical structure of the catalyst is not changed during the catalytic reaction.

Figure 7(a) compares the UV-Vis spectra for $\mathrm{V}_{2}$ and $\mathrm{Q}-\mathrm{V}_{2}$. The broad absorption band at $400 \mathrm{~nm}$ for $V_{2}$ is assigned to the charge transfer reaction of $\mathrm{O}^{2-} \rightarrow \mathrm{V}^{5+}$ in Keggin HPA anions [36]. In contrast, the $\mathrm{O}^{2-} \rightarrow \mathrm{V}^{5+}$ band for $\mathrm{Q}-\mathrm{V}_{2}$ shifts to $340 \mathrm{~nm}$, accompanied with a large broad band from 600 to $1000 \mathrm{~nm}$ for $\mathrm{V}^{5+} \rightarrow \mathrm{V}^{4+}$. The reduced $\mathrm{V}^{4+}$ species is formed by the electron interaction between the organic cations and HPA anions [37]. Figure 7(b) shows the ESR spectra for $\mathrm{V}_{2}$ and $\mathrm{Q}-\mathrm{V}_{2}$. $\mathrm{V}_{2}$ did not exhibit a response, whereas an eight-line signal consistent with $\mathrm{V}^{4+}$ species was observed for $\mathrm{Q}-\mathrm{V}_{2}$. Therefore, both UV-Vis and ESR results reveal the presence of $\mathrm{V}^{4+}$ species in $\mathrm{Q}-\mathrm{V}_{2}$, indicating the strong electronic interaction between Keggin units and quinine. It is thus proposed that the high activity of $\mathrm{Q}-\mathrm{V}_{2}$ for the hydroxylation of benzene is associated with not only the increased surface area and promotion of quinine hydroxyl groups but also with the redox properties of the HPA anions being improved by the electronic interaction between Keggin units and quinine. Accordingly, the lower yield obtained over the silica-supported catalyst $\mathrm{PMoV}_{2} / \mathrm{SiO}_{2}$ (Table 1, entry 9), even though it has high BET surface area, is because $\mathrm{PMoV}_{2} / \mathrm{SiO}_{2}$ lacks the strong interaction between Keggin units and quinine.

\section{Conclusions}

A new hybrid catalyst quinine-phosphovanadomolybdate $\left(\mathrm{Q}-\mathrm{V}_{2}\right)$ for hydroxylation of benzene to phenol with aqueous hydrogen peroxide was easily prepared by reacting quinine with a Keggin HPA. The catalyst formed a solid-liquid heterogeneous catalytic system and exhibited high catalytic performance, with comparable activity to its homogeneous analog, easy recoverability, and good reusability. The highly efficient performance of $\mathrm{Q}-\mathrm{V}_{2}$ was a result of its high surface area, pore volume, and promotion by quinine hydroxyl groups, as well as the redox properties of the Keggin HPA anion being improved by the strong electronic interaction between the $\pi$-electronenriched quinine framework and HPA anions.

\section{References}

[1] Hock H, Lang S. Ber Dtsch Chem Ges B, 1944, 77: 257

[2] Sheldon R A, Kochi J K. Metal-Catalyzed Oxidations of Organic Compounds. New York: Academic Press, 1981. 6

[3] Xin H C, Koekkoek A, Yang Q H, Van Santen R, Li C, Hensen E J M. Chem Commun, 2009: 7590

[4] Kusakari T, Sasaki T, Iwasawa Y. Chem Commun, 2004: 992

[5] Chen X F, Zhang J S, Fu X Z, Antonietti M, Wang X C. J Am Chem Soc, 2009, 131: 11658

[6] Niwa S I, Eswaramoorthy M, Nair J, Raj A, Itoh N, Shoji H, Namba T, Mizukami F. Science, 2002, 295: 105

[7] Guo Y, Zhang X F, Zou H Y, Liu H O, Wang J Q Yeung K L. Chem Commun, 2009: 5898

[8] Khatri P K, Singh B, Jain S L, Sain B, Sinha A K. Chem Commun, 2011, 47: 1610

[9] Balducci L, Bianchi D, Bortolo R, D’Aloisio R, Ricci M, Tassinari R, Ungarelli R. Angew Chem Int Ed, 2003, 42: 4937

[10] Chen Y W, Lu Y H. Ind Eng Chem Res, 1999, 38: 1893

[11] Nomiya K, Yagishita K, Nemoto Y, Kamataki T A. J Mol Catal A, 1997, 126: 43

[12] Nomiya K, Nemoto Y, Hasegawa T, Matsuoka S. J Mol Catal A, 2000, 152: 55

[13] Zhang J, Tang Y, Li G Y, Hu C W. Appl Catal A, 2005, 278: 251

[14] Liu Y Y, Murata K, Inaba M.J Mol Catal A, 2006, 256: 247

[15] Bourlinos A B, Raman K, Herrera R, Zhang Q, Archer L A, Giannelis E P. J Am Chem Soc, 2004, 126: 15358

[16] Ettedgui J, Neumann R. J Am Chem Soc, 2009, 131: 4

[17] Haimov A, Neumann R.J Am Chem Soc, 2006, 128: 15697

[18] Zhang W H, Leng Y, Zhao P P, Wang J, Zhu D R, Huang J. Green Chem, 2011, 13: 832

[19] Leng Y, Wang J, Zhu D R, Zhang M J, Zhao P P, Long Z Y, Huang J. Green Chem, 2011, 13: 1636

[20] Zhao P P, Leng Y, Zhang M J, Wang J, Wu Y J, Huang J. Chem Commun, 2012, 48: 5721

[21] Zhao P P, Zhang M J, Wu Y J, Wang J. Ind Eng Chem Res, 2012, 51: 6641

[22] Leng Y, Wang J, Zhu D R, Shen L, Zhao P P, Zhang M J. Chem Eng J, 2011, 173: 620 


\title{
Graphical Abstract
}

Chin. J. Catal., 2013, 34: 2118-2124 doi: 10.1016/S1872-2067(12)60631-7

Direct hydroxylation of benzene to phenol with hydrogen peroxide catalyzed by a quinine-heteropolyacid hybrid

Pingping Zhao, Yu Zhou, Yangqing Liu, Jun Wang*

Nanjing University of Technology

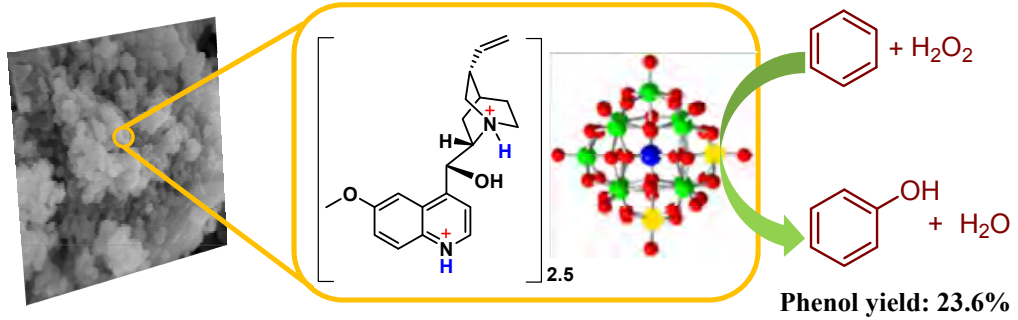

A quinine-modified phosphovanadomolybdate hybrid is developed as a heterogeneous catalyst for hydroxylation of benzene. The redox properties of the heteropolyanion are improved by quinine, accounting for its excellent catalytic performance.

[23] Zhao P P, Leng Y, Wang J. Chem Eng J, 2012, 204-206: 72

[24] Leng Y, Ge H Q, Zhou C J, Wang J. Chem Eng J, 2008, 145: 335

[25] Sumimoto S, Tanaka C, Yamaguchi S T, Ichihashi Y, Nishiyama S, Tsuruya S. Ind Eng Chem Res, 2006, 45: 7444

[26] Misono M. Chem Commun, 2001: 1141

[27] Brückner A, Scholz G, Heidemann D, Schneider M, Herein D, Bentrup U, Kant M. J Catal, 2007, 245: 369

[28] Yori J C, Grau J M, Benitez V M, Sepulveda J. Appl Catal A, 2005, 286: 71

[29] Yan X H, Zhu P L, Fei J B, Li J B. Adv Mater, 2010, 22: 1283

[30] Zhang J, Wang A J, Li X, Ma X H. J Catal, 2011, 279: 269
[31] Rocchiccioli-Deltcheff C, Fournier M. J Chem Soc, Faraday Trans, 1991, 87: 3913

[32] San Felices L, Vitoria P, Gutierrez-Zorrilla J M, Reinoso S, Etxebarria J, Lezama L. Chem Eur J, 2004, 10: 5138

[33] Vimont A, Travert A, Binet C, Pichon C, Mialane P, Secheresse F, Lavalley J C. J Catal, 2006, 241: 221

[34] Templeton A C, Wuelfing W P, Murray R W. Acc Chem Res, 2000, 33: 27

[35] Corma A, Esteve P, Martnez A.J Catal, 1996, 161: 11

[36] Rao G R, Rajkumar T. Catal Lett, 2008, 120: 261

[37] Yamase T. Chem Rev, 1998, 98: 307

\section{奎宁-杂多酸杂化催化剂催化 $\mathrm{H}_{2} \mathrm{O}_{2}$ 为氧源的苯羟基化反应}

\author{
赵萍萍, 周瑜, 刘阳庆, 王 军 ${ }^{*}$ \\ 南京工业大学化学化工学院材料化学工程国家重点实验室, 江苏南京210009
}

摘要: 将奎宁与Keggin结构磷钿钒杂多酸结合制备出一种新颖的多相苯羟基化杂化催化剂, 采用傅里叶变换红外光谱、紫外-可见 光谱、X射线衍射、扫描电镜、热重、 $\mathrm{N}_{2}$ 吸附-脱附和CHN元素分析等表征手段对催化剂进行了分析. 结果表明, 该催化剂是一种 具有较高比表面积和孔体积的半无定形有机杂多酸盐. 在 $\mathrm{H}_{2} \mathrm{O}_{2}$ 为氧源的苯羟基化反应中, 杂化催化剂引导了液-固两相催化体系, 表现出较高催化活性和重复使用稳定性. 催化剂中奎宁与杂多阴离子间的氢键和电子相互作用赋予了其高熔点和难溶性, 而高 比表面积和因奎宁而改善的杂多阴离子的氧化还原性是其获得优异催化性能的主要原因. 这为多相苯羟基化反应提供了一种新 的且制备便捷的基于多金属氧酸盐的高效催化剂.

关键词: 杂多酸; 多金属氧酸盐; 苯羟基化; 多相催化; 苯酚

收稿日期: 2013-05-16. 接受日期: 2013-05-30. 出版日期: 2013-11-20.

*通讯联系人. 电话: (025)83172264; 电子信箱: junwang@njut.edu.cn

基金来源：国家自然科学基金(21136005).

本文的英文电子版由Elsevier出版社在ScienceDirect上出版(http://www.sciencedirect.com/science/journal/18722067). 